\title{
CUIDADOS DE LA SALUD EN EL ÁMBITO FAMILIAR Y DOMÉSTICO: UN ROL DE GÉNERO. REMEDIOS TRADICIONALES USADOS EN VILLENA (ALICANTE)
}

ELEUTERIO GANDIA HERNÁNDEZ

Universidad de Alicante

\section{INTRODUCCIÓN}

En el ámbito familiar y doméstico se llevan a cabo una serie de cuidados no profesionales de la salud que constituyen el núcleo esencial de cualquier sistema asistencial y que incluyen aquellas actividades que, al margen de la medicina profesional, utilizan recursos y saberes del acervo cultural en el que está inmersa la familia.

Numerosas investigaciones recientes han evidenciado que cerca del $75 \%$ de todos los cuidados para la salud se producen en el contexto informal de la familia, siendo en ella la mujer protagonista de las funciones cuidadoras y la que en muchos casos toma las decisiones más relevantes para la salud de sus miembros ${ }^{1}$.

Este tipo de cuidados ha sido definido por la Antropología de la Salud como el ámbito del cuidado lego o profano de la salud (health lay care) y entre los diversos niveles de atención que pueden diferenciarse en él hay que señalar los que se vienen catalogando como autocuidado y autoatención.

Se concibe el autocuidado como el primer nivel de atención referido al individuo y a sus prácticas domésticas cotidianas de promoción de la salud entre las que destacan los hábitos personales e íntimos que constituyen parte del cuidado de nosotros mismos (ducharse, lavarse los dientes, etc.). La autoatención implica las conductas que se activan a nivel doméstico en caso de ruptura del bienestar que están siempre mediadas por el influjo sociocultural y que tienen

1. En nuestra tesis doctoral Sistema de creencias y prácticas ligadas a la salud en Villena (Alicante), Universidad de Alicante, 2000, dimos cuenta de los trabajos de investigación realizados hasta la fecha en este sentido. 
en cuenta creencias y remedios tradicionales conocidos por anteriores prescripciones o recomendados por familiares, vecinos, amigos y otros significantes de las redes sociales informales ${ }^{2}$.

Estas creencias y remedios que constituyen la esencia de la resolución de problemas en el ámbito familiar y doméstico se aplican, por lo general, a dolencias de gravedad leve o moderada y tienen su origen en muchas ocasiones en la tradición empírica, pero en otras, se han formulado o reformulado a través de influencias y relaciones de todo tipo incluidas las que se producen con la práctica médica.

En este trabajo, que es parte de otro estudio más amplio de tipo etnográfico sobre medicina popular, describimos las creencias y remedios más significativos que en el ámbito familiar y doméstico mantiene y utiliza buena parte de la población de la ciudad de Villena.

La localidad está situada en el noroeste de la provincia de Alicante, en una importante encrucijada de caminos entre las comunidades autónomas de Valencia, Murcia y Castilla la Mancha. Históricamente, su situación fronteriza, su carácter de enclave estratégico y su pertenencia a reinos diferentes en distintas épocas, le han proporcionado un bagaje colmado de influencias culturales de todo tipo. En la actualidad es la cabecera de la comarca del Alto Vinalopó. Por número de habitantes (33.455), es el municipio más poblado de la comarca y uno de los de mayor peso demográfico de la provincia. Se trata de una población urbana de tamaño medio, desarrollada y moderna, con un dinamismo social y económico considerable y muy receptiva a proyectos innovadores.

Para la identificación de las creencias y remedios hemos contado con la colaboración de treinta informantes de distintas edades y sexo, mayoritariamente mujeres, quienes, a través de entrevistas semiestructuradas, han descrito tanto aquellos procedimientos que todavía se llevan a cabo como aquellos ya abandonados pero que son susceptibles de formar parte de una recopilación de folklore popular.

\section{REMEDIOS TRADICIONALES}

\subsection{La visión y los problemas oculares}

La visión y los ojos son objeto de especial protección en el ámbito doméstico, de ahí que se mantengan creencias y remedios populares que no suelen comportar riesgos ni tienen efectos secundarios y cuya eficacia está probada empíricamente en muchos casos. Los remedios aplicados que hemos podido identificar se usan para tratar la conjuntivitis, el orzuelo y para la extracción de cuerpos extraños.

2. El cuidado a la salud en el ámbito doméstico ha sido explorado principalmente por la antropología médica. MENÉNDEZ, E.: «Grupo doméstico y proceso salud/enfermedad/atención: del teoricismo al movimiento continuo", Cuadernos Médico Sociales, 59 (1992), pp. 3-18, trata del modelo de autoatención, que tiene por centro a la mujer, y constituye el primer nivel real de atención a la salud 
No es habitual que en el ámbito doméstico se diagnostique una conjuntivitis como lo hace la medicina oficial pero sí que es creencia extendida que, cuando alguien tiene los ojos enrojecidos y sensación de arenilla, debe ser tratado con remedios simples antes de acudir al médico.

Lo más frecuente en estos casos es la utilización de un remedio antiguo y eficaz que consiste en la aplicación directa sobre el saco conjuntival de unas gotas de agua en la que previamente se ha disuelto un poco de sal ${ }^{3}$.

Se utiliza también con mucha frecuencia la aplicación directa sobre el ojo de las gotas resultantes de la preparación de una infusión fría de manzanilla, preferiblemente de monte (matricaria chamomilla L.) ${ }^{4}$.

La aplicación de gotas de limón exprimido directamente sobre el saco conjuntival es también remedio conocido desde muy antiguo y aunque, en la actualidad, los antibióticos resuelven sin dificultad estos problemas, hay muchas personas que siguen utilizando el remedio al iniciarse los síntomas buscando con ello evitar las pérdidas de tiempo, desplazamientos o gastos económicos no previstos, propios de la medicina oficial ${ }^{5}$.

El orzuelo es una afección fácilmente distinguible en el ámbito popular, consiste en la formación en el párpado del ojo de un pequeño grano o absceso de color blanquecino con bordes enrojecidos ${ }^{6}$.

La información obtenida permite describir varias formas de tratamiento de esta afección ocular pero debemos señalar que, aunque conocidos por casi todas las personas que han participado en el estudio, su práctica está en fase de abandono porque según afirman, prefieren recurrir a la medicina oficial. Una de las informantes de avanzada edad se expresa de la siguiente manera: «Estas cosas las hacíamos antes porque no podías ir a la farmacia y no ibas a llamar al médico, bueno si se complicaba hacías lo que fuera pero antes probabas con la llave o la manzanilla».

El procedimiento de la llave al que se refiere esta informante consiste en la aplicación directa sobre el propio orzuelo de un objeto metálico que se mantiene en contacto un tiempo determinado. Entre los objetos metálicos, se recomienda como preferible el uso de una llave de las que se usaban para abrir y cerrar puertas antiguas. Otra de las informantes, también mayor, concreta lo siguiente: «Tenía que ser una llave de esas grandes que estaban como huecas. Eso iba muy bien, y aquí lo hemos hecho toda la vida».

3. De hecho, la medicina oficial lo utiliza también en forma de suero fisiológico que no es ni más ni menos que una solución de agua y sal.

4. Es una planta muy abundante en el término municipal que florece a finales de abril y primeros de mayo. Son numerosas las personas que la recolectan para todo el año por sus múltiples aplicaciones en problemas de salud.

5. Según información de la Jefa de Servicio de Oftalmología del Hospital de Elda que es el de referencia para la ciudad, resulta evidente que con este remedio se crea un entorno ácido en el ojo que impide la proliferación de determinados microorganismos, aunque si se prolonga demasiado su aplicación puede originar una queratitis.

6. Para la medicina oficial es la manifestación de la infección estafilocócica de un folículo piloso. 
El recurso de la manzanilla consiste en la aplicación sobre el propio orzuelo de un algodón empapado en una infusión caliente de manzanilla. En este caso, a diferencia de la recomendación para la conjuntivitis, la manzanilla debe estar caliente.

Hay que señalar también que para el tratamiento del orzuelo se recomendaba hasta no hace muchos años un procedimiento que utilizaba la curación por «transferencia» a otra persona, que consistía en colocar un montón de doce piedras pequeñas, que tenían que caber en una mano, en un lugar de paso, de forma tal que resultara fácil que alguien lo pisara o lo deshiciera. Este procedimiento es conocido por gran parte de las personas participantes en el estudio quienes afirman que al deshacerse o pisarse el montón de piedras el orzuelo desaparece y le pasa a la persona que lo ha deshecho?.

Los ojos son, en situaciones accidentales, objeto de agresión por cuerpos extraños que, habitualmente, con el lagrimeo se desplazan hacia el saco conjuntival donde es más fácil su extracción. En otras ocasiones, por las características del objeto que se incrusta en el ojo la extracción es un poco más complicada.

En ambos casos, y siempre que el afectado o su entorno considere el hecho no especialmente dificultoso, la solución se busca mediante remedios caseros de entre los que destacamos, por seguir siendo usados en la actualidad y sobre todo por su singularidad, dos de ellos.

El primero, consiste en la utilización de un botón pequeño, de los que suelen llevar las camisas, que se introduce con cuidado en el ojo afectado donde queda depositado hasta que desaparece el cuerpo extraño ${ }^{8}$.

El segundo procedimiento está recomendado en los casos en los que la presencia de cuerpos extraños sólo afecta a un ojo. Consiste en frotarse suave pero enérgicamente el ojo no afectado por la presencia del cuerpo extraño.

Tanto en el caso del botón como en el de restregarse el ojo no afectado, resulta evidente que lo que se provoca es un aumento del lagrimeo que favorece la eliminación del cuerpo extraño.

\subsection{Lesiones y problemas de la piel}

Son varios los problemas o lesiones de la piel que encuentran su remedio en el ámbito doméstico; en unos casos se utilizan ante la necesidad de dar una respuesta inmediata que no admite demora, como es el caso de picaduras y quemaduras; en otros, por la persistencia de un problema que se cree puede resolverse sin necesidad de acudir al médico.

7. Otros remedios "por transferencia» en el caso del orzuelo, aunque distintos al que hemos recogido en Villena, han sido descritos en otros lugares de las tres provincias de la comunidad valenciana por SEIjó Alonso, F.G.: Curanderismo y medicina popular, Alicante, Biblioteca Alicantina, 1974.

8. La Jefa de Servicio de Oftalmología del Hospital de Elda, mencionada anteriormente, nos informa que algunos pacientes atendidos en el hospital refieren haberlo utilizado y relata la anécdota reciente de un paciente al que hubo de intervenir porque se le había olvidado retirar el botón y se había enquistado. 
Los problemas de la piel para los que hemos identificado remedios no profesionales son los relacionados con las verrugas, granos ciegos, sabañones, escocíos, grietas en talones y manos, cercadedos, quemaduras, picaduras de insectos, borradura, y arrugas en la cara.

Las verrugas son tumores de la piel muy frecuentes en la infancia y adolescencia que en el ámbito familiar no suelen ser consideradas como un problema médico, no son causa de ninguna enfermedad, no pueden afectar a un órgano interno ni pueden causar cáncer de piel, aunque en ocasiones pueden ser dolorosas. Muchas veces desaparecen espontáneamente pero en personas adultas suelen ser más persistentes.

Cuando presentan un tamaño considerable o aparecen en cantidad en zonas visibles, pueden convertirse en un problema estético desagradable. Uno de los hombres de edad mediana que tiene un negocio de atención directa al público se manifiesta de la siguiente manera:

«No sé cómo ni por qué a mí se me llenaron las manos de verrugas y parecía un eccehomo, no me dolían ni me picaban ni nada pero tenía una vergüenza y complejo impresionantes. Así que a todo el que venía al taller le preguntaba y si me decían haz esto o haz lo otro, yo lo hacía. Hice lo de los ajos, lo de la manzana, lo de la llave y más cosas que no me acuerdo. Al final se me cayeron solas un día pero no me digas cual de todos fue el remedio bueno porque no lo sé, lo que si sé es el descanso que se me quedó, ah, y que no me han vuelto a salir.»

Aunque «tener verrugas» es una de las razones por las que muchas personas en Villena recurren a los servicios de los curanderos, antes de utilizar este recurso el ámbito familiar y doméstico recomienda soluciones basadas en creencias populares, de entre las que hemos identificado varias de ellas.

Un grupo de estos remedios son de los considerados «por contacto» ya que ponen en contacto algún tipo de producto o sustancia con la verruga.

Otro de los hombres participantes en el estudio nos da cuenta de un remedio que utilizaba su abuelo que, según él, era muy efectivo y que consiste en pegar directamente sobre la verruga o verrugas cinta aislante que no debe quitarse hasta que no se despegue por sí sola, momento éste en el que desaparece la verruga ${ }^{9}$.

Son varias las personas entrevistadas que nos informan de la eficacia de otro procedimiento consistente en la aplicación directa sobre la verruga o verrugas

9. El periódico El Mundo del día 19 de octubre de 2002, en el suplemento de Salud, se hace eco de un estudio publicado esa misma semana en Archives of Pediatric and Adolescent Medicine, en el que un grupo de investigadores de EE.UU dice haber dado con un sistema más eficaz, barato y cómodo que la crioterapia para curar las verrugas; lo califican también de indoloro y sorprendente y consiste en la aplicación de una simple cinta adhesiva aislante. El procedimiento, tal como se describe, «supone la aplicación sobre la verruga de la cinta durante dos meses y con la siguiente rutina: la tira, que debía ser de un tamaño suficiente para tapar la lesión, se cambiaba cada seis días (salvo si se despegaba antes). Entre una y otra, se mojaba la verruga en agua y se frotaba suavemente con una lima o una piedra pómez. A la mañana siguiente se volvía a colocar el dispositivo seis días más. Las verrugas desaparecieron en el $85 \%$ del grupo que usó el adhesivo respecto al $60 \%$ del tratado con crioterapia. 
de la «leche», que suelta al cortar el tallo, la planta que unas veces denominan "leche eterna» y otras "lechera». Se refieren a la planta de la familia de las euforbiáceas conocida como «lechetrezna» (Euphorbia helioscopio L.).

Esta planta crece espontáneamente en terrenos baldíos, campos soleados, caminos, ribazos, etc. En Villena es muy fácil encontrarla durante el verano en la zona llamada de "el Pinar». Se caracteriza por poseer un látex que mancha la piel de donde probablemente se origine el nombre de «leche eterna» que le dan algunos informantes. Probablemente porque es muy abundante en látex, es por lo que otros le llaman «lechera».

De la utilización de este remedio en la actualidad ${ }^{10}$ me deja constancia el hombre más joven de los que han participado en el estudio con las siguientes palabras: «№ lo sabías? Eso es lo mejor que hay para las verrugas. Mira, yo tenía dos el mes pasado aquí en el brazo, me puse una gotica en cada una y ya lo ves, ni señal me ha quedao».

Un grupo de remedios conocidos por las personas participantes en el estudio consiste en arrojar sobre un tejado objetos concretos o productos de la tierra. Uno de ellos es el de contar las verrugas, separar tantos dientes de ajo como verrugas contadas y arrojarlos a un tejado puestos de espaldas a él ${ }^{11}$.

Son varios los informantes que recomiendan atar una manzana partida por la mitad con un hilo y cogiendo el extremo del hilo tirarla a un tejado. Así lo manifiesta uno de los informantes masculinos: "Yo tenía 120 verrugas, hice lo de tirar la media manzana atada con un hilo a un tejao porque me lo dijo mi mujer y se me fueron enseguida, y ya no me han vuelto a salir».

Otro de los remedios de este tipo, conocido por la casi totalidad de los informantes, es el de coger una llave de puerta vieja que no sirva y arrojarla también a un tejado, vuelto de espaldas al mismo.

Soler afirma que "es creencia popular que las verrugas se quitan si se ponen a secar tantos caracoles como verrugas se tengan $»^{12}$. Muchos informantes conocen esta creencia pero ninguno la ha utilizado.

Un remedio del que nos dan cuenta varios informantes consiste en hacer, con las manos colocadas detrás de la espalda, tantos nudos como verrugas se tengan. Una vez hechos los nudos hay que dejarlos caer al suelo y marcharse sin mirarlos. Las variaciones de este procedimiento se encuentran en el material utilizado para hacer los nudos ya que aunque la mayoría nos dice deben hacerse con hojas de esparto, una de las mujeres informantes de avanzada edad afirma que debe hacerse con grama: "Tú tenías que coger una tira de grama y con las

10. Ratificación de este remedio la encontramos en VICENT MARTINEZ, C.: «Lechetrezna Euphorbia", Botanical on line, (2006); url: http://www.botanical-online.com/alcaloideseuphorbia.htm, donde se afirma respecto de esta planta: «El látex es especialmente activo, se ha utilizado en medicina casera para eliminar los callos o las verrugas aplicando látex sobre la zona afectada».

11. SeijÓ Alonso, F.G.: Op.cit. refiere: «en Villena tiran dientes de ajos dentro de un horno. Al consumirse se curan las verrugas». Ninguno de los informantes que han participado en este estudio dice conocer este remedio.

12. Soler GarCía José Ma: Diccionario Villenero, Alicante, Instituto de Cultura Juan Gil Albert de la Diputación Provincial de Alicante y Fundación José Ma Soler de Villena, 1993, p. 66. 
manos detrás hacer un nudo sin mirar. Cuando estaba hecho el nudo se dejaba caer y te ibas. Unas veces se quitaban y otras no».

Otro de los problemas de la piel para el que el ámbito doméstico conoce remedios es el que popularmente se identifica como grano ciego y al que los informantes definen como "aquel que no tiene punta». Se trata de un enrojecimiento y abultamiento de la piel similar a un grano en el que no es posible distinguir el punto blanco de pus a través del cual es posible, apretando, liberarlo de la misma.

Para su curación, y con el fin de evitar las molestias, se considera necesario ablandar la piel que recubre el grano para que resulte fácil eliminar el líquido infectado apretando lateralmente. Por ello, los remedios identificados tienen como finalidad producir este ablandamiento utilizando diversos productos, siendo los más conocidos los siguientes:

-Asar, preferentemente en el horno, una cebolla y aplicarla muy caliente sobre la zona afectada porque como afirma una mujer de mediana edad: "Es que así se blandea el grano y se abre».

- Aplicar sobre el grano la parte carnosa de un tomate muy maduro partido previamente por la mitad. Este remedio también se utiliza untando el tomate con manteca de cerdo. Afirma a este respecto otra mujer de mediana edad: "A mi hermano cuando era joven le salían muchos y mi madre le ponía por la noche medio tomate con manteca sujeto con una venda; al día siguiente cuando se levantaba ya se le había abierto».

- Aplicar una gasa con ungüento Cañizares que antes debe calentarse. Afirma otra de las mujeres al respecto: "Primero había que poner paños muy calientes, muy calientes, varias veces; y luego el ungüento Cañizares, y cuando le veíamos una punta lo apretábamos de los laos. Eso era lo mejor, el ungüento Cañizares».

El frío extremo del invierno en Villena facilita que, sobre todo a niños y personas mayores, les aparezcan durante el invierno y localizados en zonas distales del cuerpo, tales como punta de los dedos de los pies y las manos, orejas y nariz, unas inflamaciones de la piel que suelen producir picor y dolor y que son conocidas como sabañones.

Popularmente se consideran producidos por la confluencia de tres factores principales: la predisposición de algunas personas, el frío y la alimentación inadecuada. Así he recogido esta creencia de dos informantes, una mujer y un hombre, ambos de edad mediana:

"Aún hay gente que tiene sabañones en invierno, pero mucha menos que antes, no ves que ahora comemos mejor».

«De pequeños, en los Salesianos, casi todos los chiquillos teníamos sabañones, ¡qué podías esperar entre el frío que hacía y la alimentación que nos daban!; pero tú fíjate que a los que eran de buena familia no les salían».

Los remedios utilizados tienen por finalidad aliviar el picor y el dolor para lo que se aconseja restregar la zona afectada con dientes de ajo pelados y crudos. 
También relatan algunos informantes que es bueno restregarlos con la orina de la persona que los padece.

Se dice en Villena que uno "está escocío» cuando se produce un enrojecimiento molesto y doloroso de la piel en la parte interna de los muslos por efecto del sudor y la rozadura del pantalón.

Para estas escoceduras los consejos más repetidos por los informantes son los de utilizar la planta conocida como "panicardo» llevando colgado al cuello con un cordón una parte de la misma. Las variaciones en el remedio se encuentran en que unos informantes dicen que hay que utilizar la raíz del panicardo e introducirla en una bolsa de tela pequeña que se cuelga al cuello, y otros afirman que hay que coger un trozo del tallo seco, hacerle un pequeño agujero y pasar por él un cordón. Por extraño que pueda parecer el remedio, tenemos constancia de su uso actual. Así nos lo explica una de las mujeres participantes en el estudio:

«Mi hijo mayor, no sé si del fútbol o de qué, cada dos por tres estaba con los muslos escaldaos, le dijeron lo del panicardo y cosa santa, ya no le ha vuelto a pasar, él ni se lo creía pero desde entonces siempre lo lleva al cuello».

Otro de los remedios que nos refieren para aliviar los escocíos es el de aplicar sobre la zona afectada una mezcla de aceite y agua bien batida.

Aunque el Diccionario Villenero define "cercadedo» como «inflamación purulenta alrededor de las uñas de los dedos» ${ }^{13}$, sólo dos de las mujeres informantes conocen la palabra y su significado: «Sí que sé lo que es, eso se llamaba al uñero que te se ponían los dedos malos que te dolían como si te dieran golpes por dentro y los escaldábamos».

Se trata de la infección que se produce en una uña caracterizada por un enrojecimiento alrededor de la misma, con un reborde prominente y una gran sensación de calor y dolor. Si tiene lugar en las uñas de los pies se identifica como «uñero»; y si es en los dedos de la mano, "panadizo»; nombres éstos que sí que conocen los participantes en el estudio.

Su tratamiento está basado en lo que denominan «escaldar el dedo» afectado bien con agua sola o con una infusión de «rabogato», una planta muy abundante en diversos lugares del entorno de la ciudad que se recolecta en el periodo de floración que se produce de marzo a julio ${ }^{14}$. Esta operación se puede realizar dos o tres veces al día y se recomienda después de llevarla a cabo, si se trata de un uñero, ponerse un calcetín limpio y usar calzado que no oprima.

13. SOler GARCíA, José Ma: Op. cit., p. 73.

14. Se trata de la Sideritis Angustifolia Lag., una planta típicamente mediterránea, de base leñosa y flores de color amarillo limón que nacen de sus ramas erectas. Según informa BORJA, J.: «Sobre dos especies lagascanas mal conocidas: Sideritis tragoriganum Lag. y sideritis angustifolia Lag.», Anales del Instituto Botánico Cavanilles, 32: 2 (1975), pp. 145-150, «es una de les especies del género Sideritis, que Lagasca describe en Genera et Species Plantarutn quae aut novae sunt autnondum recte cognoscuntur (Matriti, 1816) poco conocida porque es uno de los tipos que desaparecieron con su herbario». 
En el medio doméstico una lesión típica de la piel es la de las quemaduras, siendo las más habituales las producidas con el aceite hirviendo al cocinar.

El remedio doméstico más utilizado y descrito por la mayor parte de los informantes, especialmente por las mujeres, es la aplicación de pasta dentífrica directamente sobre la zona quemada nada más producirse la quemadura extendiéndola hasta cubrir toda la superficie.

En los últimos tiempos han proliferado en el medio doméstico la presencia de macetas ornamentales con plantas de aloe y esto se ha correspondido con la difusión por distintos medios de los beneficios de esta planta para el cuidado de la piel. Entre ellos algunas informantes mujeres mencionan su utilidad para curar las pequeñas quemaduras que se producen en el desempeño de labores domésticas, lo que ha dado lugar a que cuando esto ocurre se utilice como remedio rápido la aplicación sobre la piel afectada de la parte carnosa de un trozo pequeño de hoja de aloe. Así lo afirma una de ellas: «Yo siempre me ponía pasta de los dientes cuando me quemaba cocinando, pero desde que tengo aloe en las macetas, lo utilizo porque va también muy bien».

Además de estos remedios, refieren otros más antiguos consistentes también en aplicación directa sobre la zona afectada de:

- Gachas con bicarbonato.

- Cáscara de huevo picada en un mortero hasta que se haga un polvo muy fino. Así lo explica una señora de avanzada edad domiciliada en una de las pedanías de Villena:

«No ves que entonces no había nada en la farmacia y los del campo no podíamos ir, pues usábamos lo que nos decían y teníamos más a mano. Yo siempre tenía polvico de cáscara de huevo. Cogía la cáscara de varios huevos y en un mortero la machacaba bien, bien, hasta que parecía polvo y lo guardaba porque cuando menos te esperabas te habías quemao. No ves que cocinábamos en la lumbre.»

Las picaduras de insectos es otra de las lesiones de la piel para la que los remedios caseros son muy utilizados. Es sabido que los insectos pican para defenderse y como forma de obtener alimento y que tras una picadura de un insecto se producen con frecuencia uno o más bultos rojos que suelen picar y a veces doler.

Para prevenir las molestias y picaduras de cualquier tipo de insectos se considera que lo mejor es ahuyentarlos y, para ello se recomienda colocar en la entrada de la puerta de las casas y en las dependencias en las que quieran evitarse un ramo de "tanaceto ${ }^{15}$, que es muy abundante en Villena en la zona denominada de «El Pinar», donde crece espontáneamente por ser terreno muy arenoso.

15. Con el nombre vulgar de tanaceto se conoce la planta cuyo nombre científico o latino es tanacetum vulgare. Se trata de una planta vivaz de cuyo rizoma surgen numerosos tallos erguidos y por lo general sin ramificar; las cabezuelas florales son de color amarillo intenso y se disponen en umbelas en el extremo del tallo. Toda la planta desprende un olor alcanforado y sus flores que aparecen en verano, duran sin secarse mucho tiempo. 
Entre las picaduras que pueden producir los insectos, destacan por su propensión a producir reacciones alérgicas que, en ocasiones, pueden ser graves, las de avispa y abeja. En estos casos, es creencia popular extendida que debe actuarse con rapidez para evitar en la medida de lo posible la reacción alérgica.

Como quiera que estas picaduras se suelen producir en el campo o en el medio doméstico del mismo, los remedios que se conocen y utilizan están relacionados con la rapidez de obtenerlos en él. Los que han facilitado todos los informantes son dos:

-aplicar sobre la picadura amoniaco.

-cubrir la zona de la picadura con barro. Siempre que sea posible se recomienda orinar y hacer el barro con la orina; así lo expresa uno de los informantes masculinos:

"Mi padre en el campo siempre se ha curado las picaduras de las avispas con barro hecho con su orín, pero dicen que aún es mejor hacerlo con el de un chiquillo.

Tú ten en cuenta que el orín lleva amoniaco y el amoniaco también es bueno».

En el habla popular de Villena, se llama «borradura» o "borraúra» a otra lesión de la piel para la que el ámbito doméstico prevé consejos. Se trata del sarpullido o erupción leve de pequeños granos, que suele localizarse alrededor del cuello principalmente en los niños, que están producidos por efecto del calor y que ocasionan cierta molestia y picor.

Los tratamientos que se conocen en el ámbito doméstico son sólo paliativos y, por tanto, están orientados a aliviar el picor y las molestias. Los identificados son dos:

- Frotar con alcohol de romero la zona afectada.

-Poner sobre esa zona polvos de talco. Así lo refiere una de las mujeres del estudio: "Hay que lavarse bien con agua y después ponerse polvos de talco. No se quita jeh!, porque no se quita, pero alivia bastante».

Soler informa que en Villena, "es creencia popular que si se dejan las estrébedes en el fuego se le arruga la frente a la dueña de la casa» ${ }^{16}$. Se refiere Soler a las trébedes $y$, por supuesto, a dejarlas en el fuego una vez se ha terminado de cocinar. Esta creencia que todavía recuerdan algunas mujeres mayores del ámbito rural ha perdido su vigencia por el abandono del fuego como medio para cocinar.

Sólo tres de las informantes, las tres de edad avanzada, conocen esta creencia que una de ellas explica así:

«Siempre se ha dicho que no había que dejar las estrébedes en la lumbre pa que no se arrugara la cara, igual que se decía, y mi madre lo hacía, que cuando venía una nube de esas de verano que traen tormenta, había que sacar las estrébedes a la calle pa que se fuera la nube». 


\subsection{Problemas de garganta y respiratorios}

Una de las mujeres entrevistadas nos informa del problema de su hijo que padecía asma alérgica y como consecuencia de ella se ahogaba continuamente. Después de más de un año de pruebas y tratamiento con medicamentos para la alergia sin encontrar mejoría, le recomendaron que le pusiera al niño en el pecho una piel de liebre macho adobada con anís, cosa que hizo y con la que, según relata, en menos de diez días se curó para siempre y ya no le ha vuelto a pasar.

Sorprende el procedimiento por su originalidad pero sólo hemos obtenido información de este caso. No obstante, Seijó describe un procedimiento similar en otra localidad de la Comunidad Valenciana para curar la bronquitis: «Se mata un conejo, se pela, y esa piel, caliente aún, se pega en el pecho del niño» ${ }^{17}$.

El catarro y el constipado son dos procesos que en el ámbito doméstico se suelen catalogar como idénticos, sin apenas diferencias entre ellos. Los remedios que se utilizan suelen estar encaminados a aliviar los síntomas que se presentan, destacando los que están basados en: aspiración de vahos, ingesta de bebidas alcohólicas calientes y la ingesta de tisanas.

Uno de los vahos recomendados es el que se hace introduciendo en una bolsita pequeña de tela una pastilla de alcanfor que se cuelga al cuello con una cinta, porque como nos dice una de las mujeres: «Es que así el alcanfor suelta el vaho cerca de la nariz».

Son varias las mujeres informantes que aconsejan para el constipado y el pecho cargado los vahos de "doncalisto" o "calisto" que son los nombres que en el habla popular reciben las hojas del eucalipto: «Y tú te pones unas hojicas de calisto, y verás qué pronto te hacen efecto» ${ }^{18}$.

La ingesta de coñac caliente es remedio recomendado para estos casos por casi todas las personas que han participado en el estudio que coinciden en explicar su eficacia de la siguiente manera: "El coñac calentico te hace sudar mucho y con el sudor expulsas todo lo malo que tienes». Cuando no hay coñac, dicen que lo mejor es el vino caliente. De hecho su utilización debía ser anterior a la del coñac ya que se usaba principalmente en las casas de labor, porque no era habitual que hubiera coñac ${ }^{19}$.

Las ingesta de tisanas o infusiones de plantas medicinales es también recomendación reiterada. Estas plantas son de fácil localización en el término municipal y a ellas se les atribuyen propiedades de limpieza de las vías respiratorias, bronquios y pulmones. Las plantas más recomendadas son tres tipos

17. Seijó Alonso, F.G.: Op.cit, p. 53.

18. Rojas Navarro, A.: Charraícas del Paseo, Junta Central de Fiestas de Moros y Cristianos, Villena, 1996 (Charraíca n 50), p. 50.

19. De la recomendación del vino para este proceso, hay constancia manifiesta en el lugar destinado a despacho de vinos de la Cooperativa Vinícola Na Sra. de las Virtudes, en una de cuyas paredes cuelga un cuadro con un dibujo y el siguiente texto: «El agua para el jarro y el vino para el catarro». 
de helechos de pequeño tamaño: la «ruda de muros» ${ }^{20}$, la «doradilla» ${ }^{21}$ y el "culantrillo menudo" ${ }^{22}$. Para tomarlas se preparan las tres de la misma manera: «Se coloca una onza de la planta en un litro de agua, se pone al fuego y se deja hervir durante 15 minutos, tomándose después en tazas endulzadas con miel y azúcar» ${ }^{23}$.

La tos es un síntoma que se suele relacionar acompañando al catarro o constipado. Los informantes distinguen remedios diferentes según se trate de tos seca o tos que se acompaña de mucosidad. En el caso de la tos seca distinguen también entre la que es diurna y la que de forma persistente se presenta por la noche. En este caso los remedios que describimos se siguen usando en la actualidad.

Para la tos seca diurna se aconseja:

-Introducir una cebolla pelada en agua con azúcar y dejar que se macere varias horas; colarla y beberse el caldo.

-Hacer un preparado con medio limón, miel y unas gotas de anís seco.

Cuando la presentación es nocturna y la tos es persistente se aconseja partir una cebolla por la mitad y colocarla en la mesita de noche; los vahos que despide aliviarán la tos o la eliminarán.

Cuando la tos se presenta con mucosidad, en la actualidad se recomiendan principalmente los vahos descritos en el caso del constipado, pero un remedio antiguo del que dan cuenta dos de las informantes es el que consistía en hacer un "pegao» con harina y un nabo picado en el mortero, aplicándolo muy caliente sobre el pecho. Dice una informate a este respecto: Mi madre siempre nos lo ponía y eso hacía que se moviera el moco».

Cuando una persona tiene molestias en la garganta, con independencia de su origen y de la precisión del diagnóstico, el remedio popular más conocido es el de hacer gargarismos. Se aconseja para ello utilizar mezclados algunos de los siguientes ingredientes: agua y sal; limón exprimido y miel calientes; o bien, miel disuelta en agua.

\subsection{Trastornos digestivos}

Los problemas de tipo digestivo que con mayor frecuencia se abordan, en primera instancia, a través de remedios caseros son la diarrea, el estreñimiento y la sensación de pesadez de estómago.

20. La ruda de muros, conocida también como «culantrillo blanco» (Asplenium rura-muraria I.), se encuentra en Villena en las fisuras de las rocas orientadas al norte de la sierra de "el Morrón".

21. La doradilla (Ceferach officinarum Lamarck y Decaudille) aparece en las fisuras de las rocas de casi todas las montañas de Villena.

22. El culantrillo menudo (Asplenium tridomanes L.) se encuentra en las rocas y peñascos sombríos de la Sierra Salinas, más concretamente, en la Cueva del Lagrimal.

23. VizCAino MatarRedona, A.: «Plantas medicinales existentes en el término municipal de Ville-

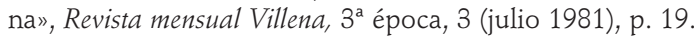


Para curar la diarrea, los remedios tradicionales más usados toman como base el arroz y el almidón; se aplican cuando ésta es considerada de carácter leve. Los identificados son:

-Hervir arroz y tras colarlo, beberse el caldo de la ebullición que en Villena se conoce como "sustancia de arroz".

-Poner arroz en agua, y después de dejar que se hinche, machacarlo en un mortero y tras colarlo, tomar el jugo resultante.

-Cocer un poco de almidón y tomarse el líquido de la cocción.

Estos remedios se acompañan generalmente con la recomendación de estar a dieta mientras dura la diarrea y de tomar líquidos, entre los que el más recomendado es el zumo de limón.

Otro remedio recomendado y usado hace tiempo es el de hacer lavados intestinales tomando "morilla roquera» que es la denominación que se da en Villena a la parietaria o cañarroya.

Entre las gentes del campo, se utilizaba un recurso accesible y que, aunque de temporada, se mantenía durante varios meses, se trata del membrillo, fruto que era abundante en las acequias, cuya recolección se hace en el mes de septiembre y que se colgaba en habitaciones secas y frías para que se mantuviese en condiciones de comerse crudo cuando apetecía o se necesitaba.

Como puede suponerse, si el membrillo es bueno para la diarrea es por su condición de alimento astringente y por ello resulta un alimento prohibido para las personas que tienen tendencia al estreñimiento.

Cuando éste se produce, o una persona tiene tendencia a ello, se aconseja tomar determinados tipos de fruta. Las frutas tradicionales más recomendadas, al decir de las informantes mujeres, son la sandía y la ciruela que, según refieren, debe de tomarse en mermelada para lo que debe cocerse con piel:

«La sandía es muy buena para el estreñimiento, no ves que la sandía alarga».

«La mermelada de ciruela que yo hago es lo mejor que puedes tomar para el estreñimiento, no ves que no la pelo, y lo que más efecto hace es la piel».

Las participantes más jóvenes recomiendan también el kiwi; en estos casos, el consejo es el de tomar uno en el desayuno todos los días.

En el caso de los niños, el estreñimiento se produce en muchas ocasiones por una atonía intestinal o espasmódica. Para vencer la retención de materias fecales que se produce, la recomendación más repetida es la de introducir suavemente en el ano de la criatura un cuerpo de diverso origen empapado en aceite al que se le da vueltas despacio y con cuidado. Los cuerpos más utilizados y conocidos son: una rama de hoja de geranio, un trozo pequeño de papel de estraza enrollado y un fósforo de tronco encerado ${ }^{24}$.

Para los casos en los que se presenta pesadez de estómago Seijó ${ }^{25}$ describe, en el caso de Villena, una cura basada en la aplicación en la zona del estómago de un emplaste o "pegao", para lo que describe dos procedimientos:

24. En la actualidad, las dificultades para obtener estos fósforos ha acabado con su utilización.

25. Seijó Alonso, F.G.: Op.cit., p. 93. 
- Amasar harina de cebada con manteca y vinagre.

- Amasar sardinas picadas en un mortero con apio, agregando harina de cebada y "arrociando» (rociando) con vinagre.

Son varios los informantes que conocen y han aplicado estos pegaos aunque, como explica una de las mujeres, hay que hacerlos con otra composición: «Yo lo que hago es un pegao con arroz, manteca y leche machacados, lo caliento y lo pongo sobre el estómago; esto hay que hacerlo durante siete días».

\subsection{Trastornos del tracto urinario}

En el ámbito doméstico el trastorno urinario que suele tratarse es el debido a la retención de la orina que, en muchos ocasiones, se manifiesta con la aparición de edemas en los miembros inferiores. En estos casos es creencia extendida que hay que limpiar y depurar.

Para ello se recomienda usar infusiones, utilizando para ello plantas de fácil y asequible recolección de las que existen el término municipal. Las más usadas son la cola de caballo ${ }^{26}$, el salicornio ${ }^{27}$ y el pelo de panocha ${ }^{28}$.

Una de las informantes es muy explícita concretando la forma en que debe utilizarse el salicornio mezclado con el pelo de panocha:

«Yo al primero que se lo oí recomendar fue a don Esteban Barbado. Hay que tomarlo en infusión y para prepararla, se mezclan en una olla con agua ramas secas de salicornio y el pelo de una panocha, se pone al fuego y cuando empieza a hervir fuerte que hace como espuma, se pone al mínimo y cuando desaparece la espuma se le vuelve a dar fuerte hasta hacer otra vez espuma y se afloja otra vez, así hay que hacerlo tres veces, lo dejas reposar y enfriar y luego te lo tomas».

\subsection{Otras creencias y remedios}

En verano las altas temperaturas son extremas en Villena y el refugio de la sombra de los árboles mitiga, aunque sea momentáneamente, el calor, por lo que es recurso muy utilizado principalmente por las personas que llevan a cabo trabajos agrícolas. Pero es creencia muy extendida que la sombra de la higuera produce dolor de cabeza y por tanto, se recomienda no cobijarse debajo de ella a pesar de que por su frondosidad proporcione sombra fresca y apetecible. Uno de los informantes, con naturalidad y cierta gracia nos dice lo siguiente: "iTú has visto algún perro tumbarse a la sombra debajo de una higuera? Pos tú lo mismo».

Para combatir los dolores de cabeza repetidos, el remedio popular más conocido es llevar una "castaña borde» en el bolsillo durante un tiempo inde-

26. Es el nombre vulgar de la Equisetum Arvense L. Se trata de una planta rizomatosa perenne con tallos erectos, huecos y duros, muy ásperos al tacto y que está considerada como una de las especies más diuréticas de todas las plantas.

27. El salicornio es el nombre que se le da a la Salicornia Europea L, planta muy frecuente en Villena que cuando se seca forma unas bolas que van rodando por los campos y las carreteras.

28. El pelo de panocha es el pelo de las mazorcas de maíz cuando están a punto de madurar. 
terminado. Este remedio lo recoge Soler ${ }^{29}$, y lo hemos recogido personalmente en tres de las entrevistas. Se aconseja como medida preventiva en las personas en las que es recurrente el dolor y para ayudar y complementar el tratamiento médico analgésico en caso de presentación aguda. En cualquier caso, advierten los tres informantes que la castaña sea "borde»; es decir, no comestible, como ocurre con el fruto de los castaños llamados de Indias.

Para la dilatación de las venas de la región anal, popularmente conocida como almorranas, se recomienda en Villena, además de darse baños de asiento con agua fría, colocar debajo de la cama habitualmente usada para dormir, un ramo seco de "tanaceto» que previamente se habrá introducido en una bolsa de tela o se habrá envuelto en papel de periódico. Así lo explica una de las mujeres:

"Cuando me operaron del grano infectao que tenía en la parte de atrás se ve que se me movieron las almorranas y tenía un dolor que pa qué. Puse debajo de la cama la bolsa con la planta esa de flores amarillas y nunca más me han molestado, pero eso sí, todos los años cambio las flores por otras nuevas».

La dentición de los niños siempre ha sido una preocupación para las madres que usan remedios para favorecerla y evitar las molestias que ocasiona a los niños. Una creencia popular antigua que se mantenía en Villena, pero que sólo conocen dos de las mujeres de avanzada edad que han participado en la investigación, es la de que la pata de un ardacho ${ }^{30}$ cortada en vivo y puesta en una bolsita colgada al cuello de los niños les facilita la dentición. Una de ellas lo explica así:

«Pa el dentar de los nenes se cogía un ardacho de los que había por el monte, que antes había muchos pero ahora no siento decir de que hayan, y los pastores les cortaban la manecica derecha, pero se la cortaban estando vivo, sin matarlo, y la metían en una bolsica y se le colgaba al cuello al nene que iban muchos con la bolsita colgá al cuello y la manecica seca dentro. Pero se hacía con el ardacho vivo y después de cortarle la mano se soltaba».

La pérdida del apetito en los niños ha sido tradicionalmente, y sigue siendo en la actualidad, otro motivo de preocupación para las madres. Para intentar solucionarlo y, al mismo tiempo, recuperar la debilidad que, se supone, llevaba aparejada, se han utilizado principalmente alimentos muy específicos o complementos alimentarios.

Entre los alimentos específicos el más recomendado ha sido el darle filetes de hígado porque existe la creencia de que esta parte de los animales engorda la sangre. De los complementos alimentarios el más popular y frecuente, al decir de varios informantes, es el aceite de hígado de bacalao. Así lo manifiesta una informante: "En cuanto mi madre veía que se nos quitaban las ganas de comer, enseguida unas cucharadas de aceite de hígado de bacalao».

29. SOler García J. Ma .: Op.cit., p. 70

30. En el lenguaje popular villenero se dice ardacho al lagarto o fardacho (lacerta lepida). 
Aunque menos frecuentes que las soluciones anteriores y, hoy en desuso, algunos informantes refieren otros dos procedimientos. Uno de ellos era el de hacer lo que llaman un novenario, que consistía en hacer tomar al niño durante nueve días seguidos un vaso pequeño de vino con una yema de huevo bien batida. El otro tiene un componente de medicina popular religiosa y consistía en hacer rogativas a San Nicolás como explica una de las mujeres.

«No sabíamos qué darles cuando se les retiraba las ganas de comer así que le rezábamos a San Nicolás que decían que era el abogao de las ganas de comer. Aquí al lado, un vecino trajo un San Nicolás pequeñico que luego llevó al santuario para que le rezáramos allí, y había mucha gente que le tenía fe».

\section{CONCLUSIONES}

- El grupo de personas entrevistadas estaba constituido por 20 mujeres y 10 hombres de edades comprendidas entre los 45 y los 82 años. Las respuestas a las preguntas sobre el conocimiento que tenían de remedios tradicionales para cada grupo de problemas muestran muy pocas diferencias por edad, pero muchas y muy significativas por sexo que son reflejo de la persistencia de diferentes roles de género en lo que se refiere al cuidado de la salud.

- Los hombres son conocedores de muy pocos remedios en comparación con los que conocen las mujeres. Los que conocen están relacionados principalmente con los problemas derivados de su actividad productiva, y referidos, principalmente, a lesiones y problemas de la piel o los derivados de su actividad física. Según refieren muchos de ellos en las entrevistas, esas cosas «son de mujeres», ellas son las que saben porque están más tiempo con los hijos que son los que dan más problemas. En varios casos nos han indicado que, si queríamos conocer más remedios y cómo se preparaban, le hiciéramos la entrevista a su mujer o a su madre. Ponen de relieve sus contestaciones algo que han concluido otros estudios: que los cuidados de salud que requieren las familias se asume en nuestras sociedades como una más de las llamadas «tareas domésticas», asociándose, por tanto, a un determinado rol de género: es cosa de mujeres.

- Las mujeres conocen con detalle varios remedios para cada uno de los problemas de los que se planteaban en las entrevistas. Afirman que desde pequeñas los aprendieron de sus madres, de sus abuelas o de las vecinas; luego, cuando los probaban con sus hijos o con sus maridos y verificaban que funcionaban bien, los seguían usando y recomendando a otras mujeres. Son, por lo que se deduce, las mujeres de la familia de origen, la observación y la experiencia, los pilares sobre los que se sostiene el saber sobre remedios tradicionales para el cuidado de la salud en el ámbito doméstico.

- Las diferencias entre los conocimientos que tienen hombres y mujeres ponen en evidencia, a nuestro juicio, una desigualdad de género en salud; por una parte es exponente de los diferentes roles de cuidado entre hombres y mujeres que están marcados e impuestos social y culturalmente y por otro, 
son manifestación de la división sexual del trabajo productivo y reproductivo.

- Estos remedios, como puede comprobarse, están basados en el uso de plantas, animales o minerales, de fácil acceso y consecución en el medio y entorno más cercano; también están basados en creencias de tipo supersticioso o sobrenatural. Parece que las mujeres sean en estos casos muy pragmáticas para el diagnóstico y los recursos terapéuticos que utilizan sin tener en cuenta modelos conceptuales ni fundamentos científicos, importándoles sólo los resultados que se obtienen. De acuerdo con Haro, este tipo de cuidados «no constituye una categoría de funciones y actividades fijas, sino que está mediatizado por una cultura popular de carácter eminentemente pragmático, que se adecua a cada episodio y que incluye los recursos pertinentes y accesibles para la satisfacción de ciertas necesidades que no son cubiertas por los ámbitos profesionales de la salud» ${ }^{31}$.

- Además de los descritos, las mujeres conocen otros remedios, que no eran objeto de este trabajo, basados en el uso de medicamentos, que han aprendido de su relación con el sistema sanitario oficial y por el uso de fármacos que el médico le recetara en situaciones anteriores. No obstante manifiestan preferir los recursos tradicionales porque, a diferencia de los medicamentos, nunca hacen daño ni tienen efectos secundarios.

31. HARO ENCINAS, J.A.: "Cuidados profanos: una dimensión ambigua en la atención a la salud», en E. Perdiguero y J.M ${ }^{a}$. Comelles (eds.): Medicina y Cultura, Barcelona, Bellaterra, 2000, pp. 101-161. 